Published in final edited form as:

Curr Opin Endocrinol Diabetes Obes. 2014 February ; 21(1): 45-50. doi:10.1097/MED.

0000000000000027.

\title{
Update on Neonatal Hypoglycemia
}

\author{
Paul J. Rozance, MD1 \\ ${ }^{1}$ Department of Pediatrics, University of Colorado Denver School of Medicine, Aurora CO
}

\begin{abstract}
Purpose of Review-Neonatal hypoglycemia is one of the most common biochemical abnormalities encountered in the newborn. However, controversy remains surrounding its definition and management especially in asymptomatic patients.
\end{abstract}

Recent Findings - New information has been published that describes the incidence and timing of low glucose concentrations in the groups most at risk for asymptomatic neonatal hypoglycemia. Furthermore, one large prospective study failed to find an association between repetitive low glucose concentrations and poor neurodevelopmental outcomes in preterm infants. But hypoglycemia due to hyperinsulinism, especially genetic causes, continued to be associated with brain injury. New advances were made in the diagnosis and management of hyperinsulinism, including acquired hyperinsulinism in small for gestational age infants and others. Continuous glucose monitoring remains an attractive strategy for future research in this area.

Summary-The fundamental question of how best to manage asymptomatic newborns with low glucose concentrations remains unanswered. Balancing the risks of over treating newborns with low glucose concentrations who are undergoing a normal transition following birth against the risks of under treating those in whom low glucose concentrations are pathological, dangerous, and/or a harbinger of serious metabolic disease remains a challenge.

\section{Keywords}

Neonatal hypoglycemia; glucose; insulin; hyperinsulinism

\section{Introduction}

Low neonatal glucose concentrations can lead to serious neurologic injury. However, there is no consensus definition or treatment strategy for neonatal hypoglycemia [1;2]. This statement published by the AAP in 1993 remains accurate today [3], “. . there is no evidence that asymptomatic hypoglycemic infants will benefit from treatment." However, early identification, prevention, and treatment of hypoglycemia in patients with defects in certain metabolic pathways or in the regulation of insulin secretion are important for long term outcomes. This leads to the situation in which the risks of over treatment in babies who are undergoing normal neonatal transition are balanced against the benefits gained by aggressive treatment of patients with potentially dangerous hypoglycemia. New data to

Paul J Rozance, MD, Associate Professor of Pediatrics, University of Colorado School of Medicine, Perinatal Research Center, Anschutz Medical Campus, F441, 13243 East $23^{\text {rd }}$ Avenue, Aurora, CO 80045, Phone: 303-724-1149, Fax: 303-724-0898, paul.rozance@ucdenver.edu 
resolve this situation remain lacking. This review instead focuses on new information regarding risk factors for hypoglcyemia, glucose measurement technology, acquired and genetic causes of pathological hyperinsulinism and the management of these patients, and neurologic outcomes in specific subsets of patients with hypoglycemia.

\section{Risk Factors for Neonatal Hypoglycemia}

In 2011 the AAP published a report on the management of hypoglycemia in late preterm (34-36 5/7 weeks gestation), infants of diabetic mothers (IDM), and small or large for gestation age infants (SGA and LGA, respectively). It did not recommend against screening other at risk groups but instead focused on the most commonly encountered newborns with asymptomatic hypoglycemia [4]. Shortly thereafter, a paper was published which prospectively determined the incidence of hypoglycemia [blood glucose concentrations less than $47 \mathrm{mg} / \mathrm{dL}$ ] in these groups of patients (514 total patients) [5]**. The study design had several advantages, including the use of bedside glucose oxidase technology for measurement, as opposed to bedside glucometer technology. Furthermore, data were collected as part of a prospective interventional trial for the treatment of hypoglycemia. Therefore, the timing and method of collection were standardized. Although blood glucose measurement could be discontinued after three normal concentrations, nearly $75 \%$ of patients had measurements made through 48 hours.

$51 \%$ of patients had a glucose less than $47 \mathrm{mg} / \mathrm{dL}$ and $19 \%$ had a glucose less than 36 $\mathrm{mg} / \mathrm{dL}$ [5], confirming the decision of the AAP to focus on these patients. This incidence is higher than other studies due to the higher numerical definition of hypoglcyemia [6-9]. 37\% of patients with a low glucose concentration had their first episode after three normal measurements, and 6\% had their first episode after 24 hours, indicating that hypoglycemia may be a concern for longer than older studies have determined and that three normal glucose concentrations do not ensure complete transition in these groups. Based on older data the AAP recommendations treated the duration of screening differently depending on which of the risk factors were present $[6 ; 10 ; 11]$. However, the Harris study found no difference in the incidence, timing, or severity of low glucose concentrations between the four groups. Unfortunately, this study could not provide evidence that any numerical cut-off for hypoglycemia is more valid than any other number [5].

Other recent papers further refined risk factors in IDM and LGA patients. Infants born to mothers with gestational diabetes mellitus (GDM) were more likely to be hypoglycemic if they had lower umbilical cord venous $\mathrm{pH}$, were LGA, had mothers who required insulin during pregnancy, and had mothers who were hyperlycemic during labor [12]. These findings are similar to those in a study of pregnancies complicated by either GDM or type 2 diabetes mellitus, in which low glucose concentrations were more frequent with LGA and increased infant ponderal index and in pregnancies which required pharmacotherapy for management of diabetes [13]. These risk factors may all be related to severity of maternal diabetes. Another study found that a pre-pregnancy BMI greater than $25 \mathrm{~kg} / \mathrm{m}^{2}$ in women with GDM also predicted neonatal hypoglycemia independent of maternal glucose concentrations [14], suggesting that factors other than glucose may be important [15]. Male sex was found to be an independent predictor of neonatal hypoglycemia in pregnancies 
complicated by GDM [16], a finding which extends previous observations in other IDM patients and was also confirmed in the a larger recent study [5;17]. Increased hypoglycemia with increased birth weight was also found in LGA newborns whose mothers did not have diabetes mellitus [18]. Another study showed that the presence of meconium stained amniotic fluid is not an independent risk factor for low glucose concentrations in asymptomatic term infants [19].

Differences in study design lead to variability in the measured incidence and make direct comparisons between studies impossible. Most of these new papers are unlikely to change clinical practice with the exception of the Harris paper. Simplifying screening protocols so that they are the same for most at risk groups of infants seems quite justified. Furthermore, some providers may wish to screen infants for a longer duration.

\section{Technology to Measure Glucose Concentrations}

The speed of traditional bedside glucometers is countered by their inaccuracies [20;21]. Because of inaccurate readings, low and borderline results should be confirmed in a central laboratory, though treatment of hypoglycemia should not be delayed [2]. Another more expensive strategy highlighted in the Harris paper that combines the accuracy of a laboratory based enzymatic assay with the speed of point of care (POC) testing is the use of blood gas analysers [5;21].

Continuous glucose monitoring sensors (CGMS) remain important to study. Validation of CGMS in 188 very low birth weight (VLBW) infants was published [22]*, confirming that CGMS is well tolerated in this population for up to a week [23]. CGMS data correlated well with POC glucometers, though with a slight tendency to overestimate low glucose and underestimate high glucose concentrations. It was slightly less accurate on the first day of life, when glucose concentrations are fluctuating and there has been less time for calibration against patient samples. Validation of the same device for less preterm newborns and term newborns who were IDM, SGA, or LGA had been previously published [24]. The device was more accurate in this study, though still less accurate on the first day of life than any subsequent days. Importantly, the device was calibrated with, and validated against, blood gas analyser glucose measurements. The importance of early and accurate calibration was highlighted by a re-analysis of this data utilizing different algorithms [25]*. CGMS offers a potential wealth of new information. But continuously obtained data presents a different set of challenges than intermittently obtained data. CGMS identifies up to three times more episodes of low glucose concentrations in neonates than intermittent blood glucose measurements [26]. The significance of these episodes for long term morbidity or how these episodes should be managed is unknown.

\section{Causes of Neonatal Hypoglycemia}

Recent studies have added to our understanding of the causes of hypoglycemia due to hyperinsulinism. Identifying hyperinsulinism is critical as management may be more aggressive because insulin inhibits the mobilization of alternative fuels for cerebral metabolism [2]. 


\section{Acquired}

Detailed clinical information on a group of 27 SGA newborns who presented with hyperinsulinism and hypoglycemia was published [27]**. 19\% of patients did not have increased insulin concentrations. Inappropriately low $\beta$-hydroxybutyrate, a ketone body, and free fatty acids in addition to clinical improvement with diazoxide confirmed the diagnosis in these patients. Furthermore, there was no correlation between plasma insulin concentrations and the maximum glucose infusion rate required to achieve normoglycemia. These results support those of a previous study and were extended to a group of 90 neonates who were not necessarily SGA, all showing that in addition to measuring plasma insulin concentrations while hypoglycemic, one should measure ketone bodies and perhaps free fatty acids to establish the diagnosis of hyperinsulinism [28;29]. Sequencing of the genes encoding the KATP channel, $K C N J I$ and $A B C C 8$, did not identify any mutations in the SGA patients [27].

Most of these infants responded to moderate doses of diazoxide, $5-10 \mathrm{mg} / \mathrm{kg} /$ day, though a few needed $15-20 \mathrm{mg} / \mathrm{kg} / \mathrm{day}$. Approximately $20 \%$ were unable to stop diazoxide before six months of age [27]. This prolonged course has been reported before [28;30]. Appropriate glucose control on less than $5 \mathrm{mg} / \mathrm{kg} / \mathrm{day}$ of diazoxide predicted successful transition off medication in all cases [27]. The incidence of hyperinsulinism in SGA patients was not determined in this study. But in an older prospective study nearly $40 \%$ of SGA newborns were found to have low glucose concentrations. Half of these had hyperinsulinism [31].

\section{Genetic}

Genetic forms of congenital hyperinsulinism and metabolic defects associated with hypoglycemia continue to be associated with the classic pattern of hypoglycemic brain injury, bilateral parieto-occipital [32;33]. Furthermore, recurrent hypoglycemia in this population leads to loss of neurogenic and neuroglycopenic signs as early as 12 weeks of age highlighting management challenges [34]. Several new responsible mutations have been identified, including mutations of two genes previously associated with hyperinsulinism, $A B C C 8$ and HNF4A [35;36], and one in a gene not previously associated with hyperinsulinism, HNF1A [36]. Next generation DNA sequencing also identified new mutations in the deep intronic regions of $A B C C 8$ and $H A D H$ and may identify other novel genetic defects [37]. Furthermore, inappropriate expression of the hexokinase gene, $H K 1$, in pancreatic $\beta$-cells may be responsible for some cases of hyperinsulinism [38;39].

Genotype-phenotype correlations were published for two large series of patients with congenital hyperinsulinism [40;41]. Mutations could be identified in 79\% [40] and 45\% [41] of patients, highlighting differences in populations studied. Despite these differences, more genetic causes were identified in diazoxide-unresponsive cases than in diazoxide-responsive cases. Similar to a previous study [42], identification of monoallelic recessive mutations in the genes encoding the KATP channel predicted focal hyperinsulinism [40], though not completely [41]. Furthermore, identification of mutations in the GLUD1, HADH, HNF4A, $H N F 1 A$, and $U C P 2$ genes were associated exclusively with diazoxide-responsive disease whereas mutations in the $G C K$ gene and recessive KATP mutations were almost all diazoxide-unresponsive. Dominant KATP mutations could be either diazoxide-responsive or 
unresponsive [40;41]. However, phenotypic variability, even among siblings with the same ABCC8 mutation, was highlighted in a recent case series [43]. A new genetic form of nonhyperinsulinemic neonatal hypoglycemia was described in a patient with pyridoxine dependent epilepsy and a novel mutation in the ALDH7Al gene [44].

\section{Management of Hyperinsulinism Associated Hypoglycemia}

One group published their experience with diazoxide for treating hyperinsulinism. Initial dosing was $5 \mathrm{mg} / \mathrm{kg} /$ day with co-administration of hydrochlorothiazide to prevent fluid retention and potassium chloride. Of the 44 patients eight were non-responders, mostly neonates. $40 \%$ had problems with fluid retention which resolved with dosing adjustment and $25 \%$ had transient GI side effects. All patients on diazoxide long term developed hypertrichosis [45]*. Although reported in the literature [46;47], pulmonary hypertension was not found [45]. Given its side effect profile and the subset of patients that are diazoxideunresponsive, other drugs are being evaluated for management of hyperinsulinism, such as glucagon like peptide-1 receptor antagonists [48].

Hypertrophic cardiomyopathy $[\mathrm{HCM}]$ in newborns with congenital hyperinsulinism was reported [49]*. The proposed pathophysiology leading to HCM in IDM patients is fetal hyperinsulinism due to increased maternal and fetal glucose concentrations [50]. Elevated fetal insulin concentrations in patients with congenital hyperinsulinism could also lead to HCM. In a retrospective review of 68 infants, ten had HCM [49]. This may have been an underestimate since only 25 patients had echocardiograms and asymptomatic HCM may be under recognized [51]. Given that the management of congenital hyperinsulinism involves increased fluid administration to provide glucose and medications with fluid retention properties, routine echocardiogram and electrocardiogram may be indicated in these patients [49].

Conventional imaging modalities are not adequate for diagnosing focal from diffuse forms of congenital hyperinsulinism [52]. Therefore, functional pancreatic imaging plays an important role in the management of these patients. Focal insulin secreting adenomas that are amenable to local resection offer the promise of a complete cure without major concerns of endocrine and exocrine pancreatic insufficiency. Pre-operative localization can help, with genetic testing [40], differentiate focal from diffuse disease and facilitate intraoperative identification of the affected tissue. One recently published systematic review demonstrated the superiority of ${ }^{18}$ fluoro-L-DOPA ( $\left.{ }^{18} \mathrm{~F}-\mathrm{DOPA}\right)$ positron emission tomography (PET) compared to other invasive interventional radiological procedures [53]. Two groups reported high sensitivity and specificity for identification of focal hyperinsulinism by ${ }^{18} \mathrm{~F}$-DOPA PET imaging. $100 \%$ of the focal lesions on pre-operative imaging were confirmed surgically to be in the predicted location $[54 ; 55]$.

The experience of one center with Roux-en-Y pancreaticojejunostomies in 23 patients for focal disease deep in the head of the pancreas was reported. This procedure was performed at a median age and size of eight weeks (as young as three weeks) and $5.8 \mathrm{~kg}$ [as small as $4.3 \mathrm{~kg}]$. Median hospital stay was 22 days. One patient developed surgical complications and two needed a subsequent operation for recurrent hypoglycemia [56]. 


\section{Outcome}

Some preterm newborns have persistent abnormalities of glucose metabolism. At the time of discharge (37-38 weeks), up to $18 \%$ (average gestational age at birth of 32 weeks) could not maintain glucose concentrations $>47 \mathrm{mg} / \mathrm{dL}$ if they missed one feed and $6 \%$ had glucose concentrations that fell and remained less than $40 \mathrm{mg} / \mathrm{dL}$ [11]. However, determining the independent impact of hypoglycemia on long term outcomes is difficult in preterm infants. A seminal observational study was published in 1988 showing that in 661 infants born with a birth weight $<1850 \mathrm{gm}$ the more often a patient had a glucose concentration less that 45 $\mathrm{mg} / \mathrm{dL}$ the worse their development was at 18 months [57]. Differences in outcome were less at 7-8 years [58].

A new study designed "to replicate the earlier study" included 566 patients who were born < 32 weeks gestation with prospectively measured glucose concentrations. Primary outcomes were to correlate glucose concentrations with developmental and psychomotor assessments at 2 and 15 years of age. No problems were found in patients that experienced repetitive glucoses less than $45 \mathrm{mg} / \mathrm{dL}$ on at least four or five different days. Results were also negative for newborns that had glucose concentrations $<36 \mathrm{mg} / \mathrm{dL}$ on at least three different days. Because samples in this study were collected at pre specified times, rather than when clinically indicated as in the earlier study, the chance of increased sampling of sicker newborns biasing results towards an association between hypoglycemia and poor outcomes was minimized. Despite the improved design, this paper does not definitively show that low glucose concentrations are safe in this population, as the authors acknowledged [59]**. Other studies, which were not specifically designed to prospectively test the impact of hypoglycemia on outcomes, nevertheless continued to identify hypoglycemia as an independent risk factor for brain injury and poor neurodevelopmental outcomes in moderately preterm and term infants [60-62].

\section{Conclusion}

Management of neonatal hypoglycemia remains controversial due to inconsistent definitions and a lack of high quality interventional trials $[1 ; 63]$. No new studies addressed these deficiencies. However, new studies have been published describing the incidence of low glucose concentrations in the four most at risk group of asymptomatic neonates and showing that repetitive low glucose concentrations are not associated with adverse long term outcomes. But the serious consequences of hypoglycemia, especially due to hyperinsulinism, have been confirmed and advances made in the diagnosis and management of these patients. Finally, newer studies continue to demonstrate the promise of CGMS for improving research and clinical care in this area.

\section{Acknowledgments}

The author is supported by NIH Grants: 1R01DK088139 and 1K08HD060688 and has no conflicts of interest. 


\section{References}

1. Koh TH, Eyre JA, Aynsley-Green A. Neonatal hypoglycaemia--the controversy regarding definition. Arch Dis Child. 1988 Nov.63:1386-1388. [PubMed: 3202648]

2. Rozance PJ, Hay WW. Hypoglycemia in Newborn Infants: Features Associated with Adverse Outcomes. Biol Neonate. 2006; 90:74-86. [PubMed: 16534190]

3. American Academy of Pediatrics Committee on Fetus and Newborn: Routine evaluation of blood pressure, hematocrit, and glucose in newborns. Pediatrics. 1993; 92:474-476. [PubMed: 8361812]

4. Adamkin DH. Postnatal glucose homeostasis in late-preterm and term infants. Pediatrics. 2011; 127:575-579. [PubMed: 21357346]

5. Harris DL, Weston PJ, Harding JE. Incidence of neonatal hypoglycemia in babies identified as at risk. J Pediatr. 2012; 161:787-791. [PubMed: 22727868] ** This paper is one of the largest and most methodologically rigorous to describe the incidence and timing of low glucose concentrations in the four most at risk groups for asymptomatic neonatal hypoglycemia.

6. Holtrop PC. The frequency of hypoglycemia in full-term large and small for gestational age newborns. Am J Perinatol. 1993; 10:150-154. [PubMed: 8476480]

7. Maayan-Metzger A, Lubin D, Kuint J. Hypoglycemia rates in the first days of life among term infants born to diabetic mothers. Neonatology. 2009; 96:80-85. [PubMed: 19225239]

8. Pildes R, Forbes AE, O'Connor SM, et al. The incidence of neonatal hypoglycemia--a completed survey. J Pediatr. 1967; 70:76-80. [PubMed: 6016809]

9. Sexson WR. Incidence of neonatal hypoglycemia: a matter of definition. J Pediatr. 1984; 105]:149150 .

10. Agrawal RK, Lui K, Gupta JM. Neonatal hypoglycaemia in infants of diabetic mothers. J Paediatr Child Health. 2000; 36:354-356. [PubMed: 10940170]

11. Hume R, McGeechan A, Burchell A. Failure to detect preterm infants at risk of hypoglycemia before discharge. J Pediatr. 1999; 134:499-502. [PubMed: 10190927]

12. Flores-le Roux JA, Sagarra E, Benaiges D, et al. A prospective evaluation of neonatal hypoglycaemia in infants of women with gestational diabetes mellitus. Diabetes Res Clin Pract. 2012; 97:217-222. [PubMed: 22537519]

13. Ramos GA, Hanley AA, Aguayo J, et al. Neonatal chemical hypoglycemia in newborns from pregnancies complicated by type 2 and gestational diabetes mellitus - the importance of neonatal ponderal index. J Matern Fetal Neonatal Med. 2012; 25:267-271. [PubMed: 21557689]

14. Garcia-Patterson A, Aulinas A, Maria MA, et al. Maternal body mass index is a predictor of neonatal hypoglycemia in gestational diabetes mellitus. J Clin Endocrinol Metab. 2012; 97:16231628. [PubMed: 22419709]

15. Catalano PM, Hauguel-De Mouzon S. Is it time to revisit the Pedersen hypothesis in the face of the obesity epidemic? Am J Obstet Gynecol. 2011; 204:479-487. [PubMed: 21288502]

16. Tundidor D, Garcia-Patterson A, Maria MA, Ubeda J, et al. Perinatal maternal and neonatal outcomes in women with gestational diabetes mellitus according to fetal sex. Gend Med. 2012; 9:411-417. [PubMed: 23089258]

17. Bracero LA, Cassidy S, Byrne DW. Effect of gender on perinatal outcome in pregnancies complicated by diabetes. Gynecol Obstet Invest. 1996; 41:10-14. [PubMed: 8821877]

18. Weissmann-Brenner A, Simchen MJ, Zilberberg E, et al. Maternal and neonatal outcomes of large for gestational age pregnancies. Acta Obstet Gynecol Scand. 2012; 91:844-849. [PubMed: 22471810]

19. Maayan-Metzger A, Leibovitch L, Schushan-Eisen I, et al. Meconium-stained amniotic fluid and hypoglycemia among term newborn infants. Fetal Pediatr Pathol. 2012; 31:283-287. [PubMed: 22432834]

20. Ngerncham S, Piriyanimit S, Kolatat T, et al. Validity of two point of care glucometers in the diagnosis of neonatal hypoglycemia. Indian Pediatr. 2012; 49:621-625. [PubMed: 22317986]

21. Scott MG, Bruns DE, Boyd JC, et al. Tight glucose control in the intensive care unit: are glucose meters up to the task? Clin Chem. 2009; 55:18-20. [PubMed: 19028817] 
22. Beardsall K, Vanhaesebrouck S, Ogilvy-Stuart AL, et al. Validation of the continuous glucose monitoring sensor in preterm infants. Arch Dis Child Fetal Neonatal Ed. 2013; 98:F136-F140. [PubMed: 22791467] * The validation of CGMS in at risk populations represents an important step in better understanding the significance of hypoglycemic episodes for short and long term outcomes.

23. Beardsall K, Ogilvy-Stuart AL, Ahluwalia J, et al. The continuous glucose monitoring sensor in neonatal intensive care. Arch Dis Child Fetal Neonatal Ed. 2005; 90:F307-F310. [PubMed: 16036889]

24. Harris DL, Battin MR, Weston PJ, et al. Continuous glucose monitoring in newborn babies at risk of hypoglycemia. J Pediatr. 2010; 157:198-202. [PubMed: 20338573]

25. Signal M, Le CA, Harris DL, et al. Impact of retrospective calibration algorithms on hypoglycemia detection in newborn infants using continuous glucose monitoring. Diabetes Technol Ther. 2012; 14:883-890. [PubMed: 22856622] * This paper highlights some of the issues that need to be addressed for acquiring accurate CGMS data.

26. Beardsall K, Vanhaesebrouck S, Ogilvy-Stuart AL, et al. Early insulin therapy in very-low-birthweight infants. N Engl J Med. 2008; 359:1873-1884. [PubMed: 18971490]

27. Arya VB, Flanagan SE, Kumaran A, et al. Clinical and molecular characterisation of hyperinsulinaemic hypoglycaemia in infants born small-for-gestational age. Arch Dis Child Fetal Neonatal Ed. 2013; 98:F356-F358. [PubMed: 23362136] ** Several new and underappreciated aspects of acquired hypoglycemia due to hyperinsulinism are reported.

28. Hoe FM, Thornton PS, Wanner LA, et al. Clinical features and insulin regulation in infants with a syndrome of prolonged neonatal hyperinsulinism. J Pediatr. 2006; 148:207-212. [PubMed: 16492430]

29. Al-Otaibi H, Senniappan S, Alam S, et al. Biochemical studies in patients with hyperinsulinaemic hypoglycaemia. Eur J Pediatr. 2013 [Epub ahead of print Jun 12].

30. Fafoula O, Alkhayyat H, Hussain K. Prolonged hyperinsulinaemic hypoglycaemia in newborns with intrauterine growth retardation. Arch Dis Child Fetal Neonatal Ed. 2006; 91:F467. [PubMed: 17056857]

31. Collins JE, Leonard JV, Teale D, et al. Hyperinsulinaemic hypoglycaemia in small for dates babies. Arch Dis Child. 1990; 65:1118-1120. [PubMed: 2248501]

32. Gataullina S, Dellatolas G, Perdry H, et al. Comorbidity and metabolic context are crucial factors determining neurological sequelae of hypoglycaemia. Dev Med Child Neurol. 2012; 54:10121017. [PubMed: 22924392]

33. Gataullina S, De LP, Dellatolas G, et al. Topography of brain damage in metabolic hypoglycaemia is determined by age at which hypoglycaemia occurred. Dev Med Child Neurol. 2013; 55:162166. [PubMed: 23205874]

34. Christesen HT, Brusgaard K, Hussain K. Recurrent spontaneous hypoglycaemia causes loss of neurogenic and neuroglycopaenic signs in infants with congenital hyperinsulinism. Clin Endocrinol [Oxf]. 2012; 76:548-554.

35. Faletra F, Snider K, Shyng SL, et al. Co-inheritance of two ABCC8 mutations causing an unresponsive congenital hyperinsulinism: clinical and functional characterization of two novel ABCC8 mutations. Gene. 2013; 516:122-125. [PubMed: 23266803]

36. Stanescu DE, Hughes N, Kaplan B, et al. Novel presentations of congenital hyperinsulinism due to mutations in the MODY genes: HNF1A and HNF4A. J Clin Endocrinol Metab. 2012; 97:E2026E2030. [PubMed: 22802087]

37. Flanagan SE, Xie W, Caswell R, et al. Next-generation sequencing reveals deep intronic cryptic $\mathrm{ABCC} 8$ and $\mathrm{HADH}$ splicing founder mutations causing hyperinsulinism by pseudoexon activation. Am J Hum Genet. 2013; 92:131-136. [PubMed: 23273570]

38. Henquin JC, Sempoux C, Marchandise J, et al. Congenital hyperinsulinism caused by hexokinase I expression or glucokinase-activating mutation in a subset of beta-cells. Diabetes. 2013; 62:16891696. [PubMed: 23274908]

39. Pinney SE, Ganapathy K, Bradfield J, et al. Dominant Form of Congenital Hyperinsulinism Maps to HK1 Region on 10q. Horm Res Paediatr. 2013; 80:18-27. [PubMed: 23859901] 
40. Snider KE, Becker S, Boyajian L, et al. Genotype and phenotype correlations in 417 children with congenital hyperinsulinism. J Clin Endocrinol Metab. 2013; 98:E355-E363. [PubMed: 23275527]

41. Kapoor RR, Flanagan SE, Arya VB, et al. Clinical and molecular characterisation of 300 patients with congenital hyperinsulinism. Eur J Endocrinol. 2013; 168:557-564. [PubMed: 23345197]

42. De LP, Fournet JC, Rahier J, et al. Somatic deletion of the imprinted $11 \mathrm{p} 15$ region in sporadic persistent hyperinsulinemic hypoglycemia of infancy is specific of focal adenomatous hyperplasia and endorses partial pancreatectomy. J Clin Invest. 1997; 100:802-807. [PubMed: 9259578]

43. Kapoor RR, Flanagan SE, Ellard S, et al. Congenital hyperinsulinism: marked clinical heterogeneity in siblings with identical mutations in the ABCC8 gene. Clin Endocrinol [Oxf]. 2012; 76:312-313.

44. Mercimek-Mahmutoglu S, Horvath GA, Coulter-Mackie M, Nelson T, Waters PJ, Sargent M, et al. Profound neonatal hypoglycemia and lactic acidosis caused by pyridoxine-dependent epilepsy. Pediatrics. 2012; 129:e1368-e1372. [PubMed: 22529283]

45. Hu S, Xu Z, Yan J, et al. The treatment effect of diazoxide on 44 patients with congenital hyperinsulinism. J Pediatr Endocrinol Metab. 2012; 25:1119-1122. [PubMed: 23329758]* This paper describes one center's experience with diazoxide in the management of hyperinsulinism.

46. Demirel F, Unal S, Cetin II, et al. Pulmonary hypertension and reopening of the ductus arteriosus in an infant treated with diazoxide. J Pediatr Endocrinol Metab. 2011; 24:603-605. [PubMed: 21932611]

47. Nebesio TD, Hoover WC, Caldwell RL, et al. Development of pulmonary hypertension in an infant treated with diazoxide. J Pediatr Endocrinol Metab. 2007; 20:939-944. [PubMed: 17937066]

48. Calabria AC, Li C, Gallagher PR, et al. GLP-1 receptor antagonist exendin-[9-39] elevates fasting blood glucose levels in congenital hyperinsulinism owing to inactivating mutations in the ATPsensitive K+ channel. Diabetes. 2012; 61:2585-2591. [PubMed: 22855730]

49. Huang T, Kelly A, Becker SA, et al. Hypertrophic cardiomyopathy in neonates with congenital hyperinsulinism. Arch Dis Child Fetal Neonatal Ed. 2013; 98:F351-F354. [PubMed: 23377780] * An important and under recognized complication of congenital hyperinsulinism is described.

50. Hay WW Jr. Care of the infant of the diabetic mother. Curr Diab Rep. 2012; 12:4-15. [PubMed: 22094826]

51. Abu-Sulaiman RM, Subaih B. Congenital heart disease in infants of diabetic mothers: echocardiographic study. Pediatr Cardiol. 2004; 25:137-140. [PubMed: 14648003]

52. Arnoux JB, Verkarre V, Saint-Martin C, et al. Congenital hyperinsulinism: current trends in diagnosis and therapy. Orphanet J Rare Dis. 2011; 6:63. [PubMed: 21967988]

53. Blomberg BA, Moghbel MC, Saboury B, et al. The value of radiologic interventions and [18]FDOPA PET in diagnosing and localizing focal congenital hyperinsulinism: systematic review and meta-analysis. Mol Imaging Biol. 2013; 15:97-105. [PubMed: 22752652]

54. Laje P, States LJ, Zhuang H, et al. Accuracy of PET/CT Scan in the diagnosis of the focal form of congenital hyperinsulinism. J Pediatr Surg. 2013; 48:388-393. [PubMed: 23414871]

55. Meintjes M, Endozo R, Dickson J, et al. 18F-DOPA PET and enhanced CT imaging for congenital hyperinsulinism: initial UK experience from a technologist's perspective. Nucl Med Commun. 2013; 34:601-608. [PubMed: 23571817]

56. Laje P, Stanley CA, Palladino AA, et al. Pancreatic head resection and Roux-en-Y pancreaticojejunostomy for the treatment of the focal form of congenital hyperinsulinism. J Pediatr Surg. 2012; 47:130-135. [PubMed: 22244405]

57. Lucas A, Morley R, Cole TJ. Adverse neurodevelopmental outcome of moderate neonatal hypoglycaemia. BMJ. 1988; 297:1304-1308. [PubMed: 2462455]

58. Cornblath M, Schwartz R. Outcome of neonatal hypoglycaemia. Complete data are needed. BMJ. 1999; 318:194-195. [PubMed: 9888932]

59. Tin W, Brunskill G, Kelly T, et al. 15-year follow-up of recurrent"hypoglycemia" in preterm infants. Pediatrics. 2012; 130:e1497-e1503. [PubMed: 23129080] ** An association of repetitive low glucose concentrations and poor developmental outcomes in preterm infants, which had been described in one of the most highly cited papers regarding hypoglycemia and outcomes, was not found. 
60. Kerstjens JM, Bocca-Tjeertes IF, de Winter AF, et al. Neonatal morbidities and developmental delay in moderately preterm-born children. Pediatrics. 2012; 130:e265-e272. [PubMed: 22778308]

61. McIntyre S, Taitz D, Keogh J, et al. A systematic review of risk factors for cerebral palsy in children born at term in developed countries. Dev Med Child Neurol. 2013; 55:499-508. [PubMed: 23181910]

62. Tam EW, Haeusslein LA, Bonifacio SL, et al. Hypoglycemia is associated with increased risk for brain injury and adverse neurodevelopmental outcome in neonates at risk for encephalopathy. $\mathrm{J}$ Pediatr. 2012; 161:88-93. [PubMed: 22306045]

63. Boluyt N, van KA, Offringa M. Neurodevelopment after neonatal hypoglycemia: a systematic review and design of an optimal future study. Pediatrics. 2006; 117:2231-2243. [PubMed: 16740869] 


\section{Key Points}

- Management of neonatal hypoglycemia continues to be plagued by a lack of data to resolve controversies around the definition, the glucose concentration at which neurologic injury may be sustained, and the concentration at which treatment should be initiated.

- Infants at risk for asymptomatic hypoglycemia [late preterm, infants of diabetic mothers, small for gestational age, and large for gestational age] may have their first low glucose concentrations after three normal measurements and even after 24 hours of age; and all four of these groups have a similar incidence of low glucose concentrations.

- The diagnosis of hypoglycemia due to hyperinsulinism cannot be made by solely measuring insulin concentrations at the time of a hypoglycemic episode, serum ketone bodies and perhaps free fatty acids should be measured during the episode as well.

- Given the increased amounts of fluid and medications with fluid retention properties required to manage patients with congenital hyperinsulinism, performing an echocardiogram to identify hypertrophic cardiomyopathy should be considered in these patients.

- While outcomes of patients with genetic causes of hypoglycemia due to hyperinsulinism remain concerning, a recent study did not confirm a previously identified association between repetitive low glucose concentrations and poor neurodevelopmental outcomes in a large group of preterm newborns. 